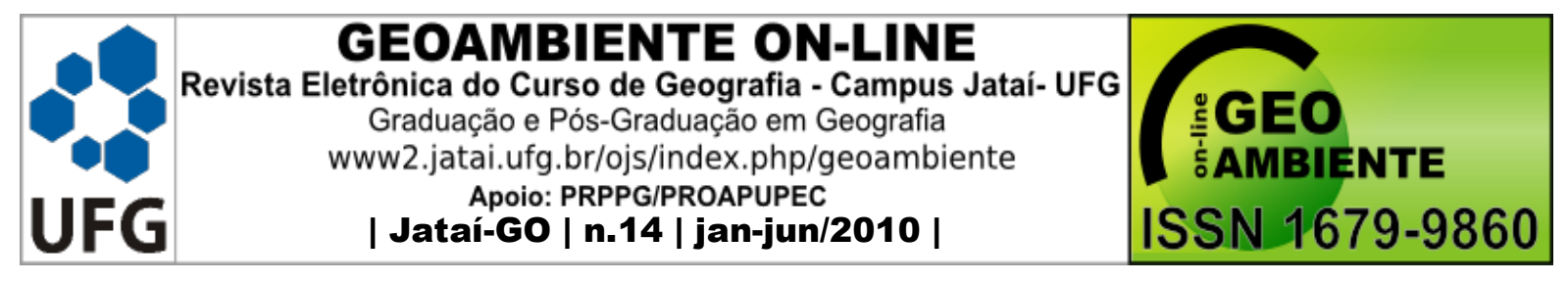

\title{
DINÂMICA DA PAISAGEM E DISTRIBUIÇÃO FITOGEOGRÁFICA DE ESPÉCIES PSAMÓFITAS EM DUNAS COSTEIRAS - BARRA DOS COQUEIROS, SERGIPE
}

\author{
Sindiany Suelen Caduda dos Santos ${ }^{1}$, Rosemeri Melo e Souza ${ }^{2}$
}

(1 - Licencida em Ciências Biológicas - UFS. Mestranda em Desenvolvimento e Meio Ambiente _ PRODEMA/UFS e membro do GEOPLAN /CNPq/UFS, Av. Marechal Rondon, S/N, Pólo de Pós Graduação, sala 1. CEP: 49100-000 - São Cristovão, SE. Telefone: (79) 2105-6796. Email: sindysuelen@ hotmail.com. 2 - Professora Associada do Departamento de Geografia - UFS. Líder do GEOPLAN-UFS. E-mail: rome@ufs.br)

\section{Resumo}

O presente artigo reporta-se à dinâmica da paisagem, bem como à distribuição fitogeográfica de espécies psamófitas em dunas costeiras da Praia de Jatobá, município de Barra dos Coqueiros, Sergipe, com vistas à apresentação dos transectos para avaliação fitogeográfica da localidade em questão e avaliação das condições atuais da paisagem, uma vez que a dinâmica paisagística dunar liga-se intimamente a fatores naturais e a componentes que se ligam a vulnerabilidade biofísica. A metodologia utilizada baseou-se no levantamento dos pontos de estudo nas Faixas de praia, dunas incipientes, semifixas e fixas da Praia do Jatobá, município de Barra dos Coqueiros, Sergipe, visando caracterizar a paisagem e coletar material botânico para posterior análise taxonômica e avaliação fitogeográfica. Em meio aos resultados demonstradores de uma vegetação sofredora de intensa depleção por conta das ações humanas e de paisagem descaracterizada, observa-se que a vulnerabilidade dunar, relacionada ao homem tem se mostrado expressiva e geradora de preocupações quanto à necessidade de medidas urgentes com vistas à preservação ambiental.

Palavras chave: Fitogeografia, Psamófitas, Dinâmica da Paisagem.

\footnotetext{
Abstract

Artigo recebido para publicação em 26 de Maio de 2009; 


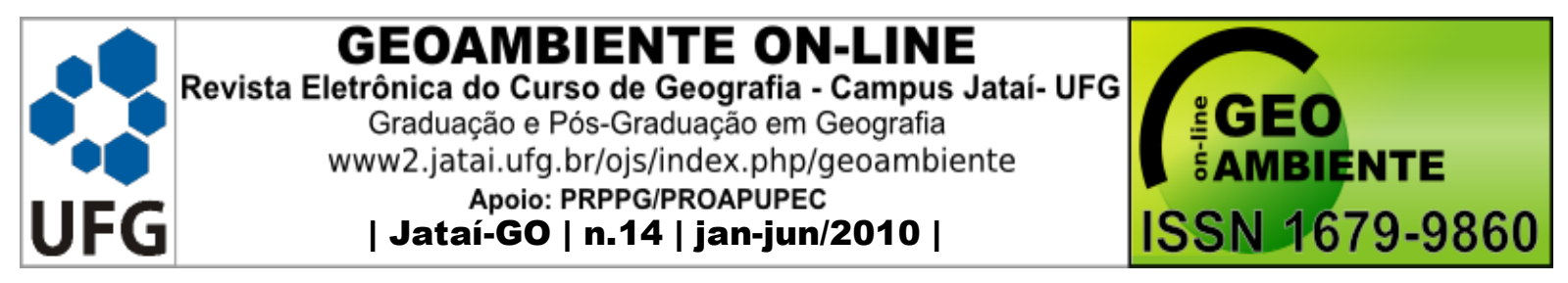

\section{LANDSCAPE DYNAMICS AND PHYTOGEOGRAPHIC DISTRIBUTION OF PSAMMOPHYTES SPECIES ON COASTAL DUNES - JATOBÁ BEACH, BARRA DOS COQUEIROS -BRAZIL.}

This article refers to the landscape dynamics, and the analysis of the phytogeographic distribution of psamophytes species on costal dunes at Jatobá Beach, city of Barra dos Coqueiros, Sergipe, with a view to submission of transects to phytogeographic assessment the study area and current conditions of the landscape, since the dynamic dune landscape is closely linked to the natural factors and components that bind to human vulnerability. The methodology was based on the survey points of the study ranges beach, incipient dunes, semifixed and fixed to the Beach Jatobá, municipality of Barra dos Coqueiros, Sergipe, to characterize the landscape and collect botanical material for subsequent taxonomic analysis phytogeographic and evaluation. Amid the results demonstrated in a severe depletion of vegetation suffering on account of human actions and landscape weakened, it is observed that the dune vulnerability in relation to man has been significant and creates concerns about the need for urgent measures in order to environmental preservation.

Keywords: Phytogeography, Psammophytes, Landscape Dynamics

\section{Resumen}

\section{DINÁMICA DEL PAISAJE, Y LA DISTRIBUCIÓN FITOGEOGRÁFICA DE LAS ESPECIES PSAMMOPHYTE EN LAS DUNAS COSTERAS - BARRA DOS COQUEIROS - BRAZIL}

En este artículo se refiere a la dinámica del paisaje, y la distribución fitogeográfica de las especies psammophyte en las dunas costeras de Jatoba, un municipio de la Barra dos Coqueiros, Sergipe, con miras a la presentación de los transectos para evaluar fitogeográfica de la localidad en cuestión y la evaluación las condiciones actuales del paisaje, ya que el dinámico paisaje de dunas se relaciona estrechamente con los factores naturales y los componentes que se conectan a la vulnerabilidad biofísica. La metodología se basó en el estudio de los puntos de estudio en el tramo de playa, las dunas semifijas y fijas incipiente la Jatoba Beach, ciudad de la Barra dos Coqueiros, Sergipe, para caracterizar el paisaje y recoger material botánico para su posterior análisis taxonómico y la evaluación fitogeográficas. En 


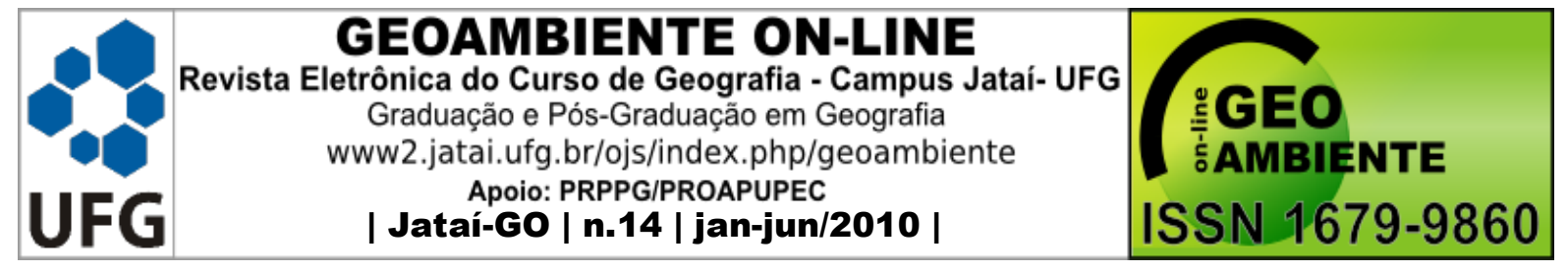

medio de los resultados de una vegetación de manifestantes que sufren de grave agotamiento debido a las acciones humanas y el paisaje no caracterizados, se observa que la vulnerabilidad de dunas, con los seres humanos ha demostrado gran inquietud y la generación de la necesidad de adoptar medidas urgentes con el fin de preservación del medio ambiente. Palabras claves: Fitogeografía, psammophyte, la dinámica del paisaje.

\section{1 - Introdução}

A Praia de Jatobá, localizada no município de Barra dos Coqueiros, Sergipe, é marcada por uma paisagem influenciada por fatores estruturantes que atuam na permanência de dunas na localidade. Por outro lado, a expressiva presença do homem tem revelado ao longo dos anos efeitos que demonstram extrema descaracterização desta área dunar e consequentemente interferem no equilíbrio dinâmico da paisagem e de seus constituintes formados por aspectos químicos, físicos e biológicos.

A singularidade da dinâmica das paisagens dunares e o estudo dos fatores que compõem o sistema paisagístico do ecossistema em questão são relevantes, posto serem as bases para o entendimento dos distintos processos integrantes da paisagem e dos impactos que surgem em meio às ações humanas.

As dunas costeiras destacam-se em meio aos diversos ecossistemas que funcionam integradamente compondo a paisagem litorânea. Conforme Oliveira (2007), o desenvolvimento das feições dunares é dependente da intensidade dos ventos, da baixa precipitação, da capacidade estabilizadora dos sedimentos exercida pelos vegetais, do tipo de sedimento e da natureza do fornecimento sedimentar.

Nesta análise, a necessidade de uma barreira que cause a retenção da areia transportada e, por conseguinte ocasione a deposição do sedimento implica afirmar que a vegetação atua de maneira determinante na formação das distintas dunas litorâneas que compõem a zona costeira.

Na Praia de Jatobá, as dunas costeiras encontram-se descaracterizadas em face da intensa especulação imobiliária e devido ao quadro de vulnerabilidade dos componentes biofísicos que interferem na permanência das paisagens naturais e na relação harmoniosa dos sistemas. 


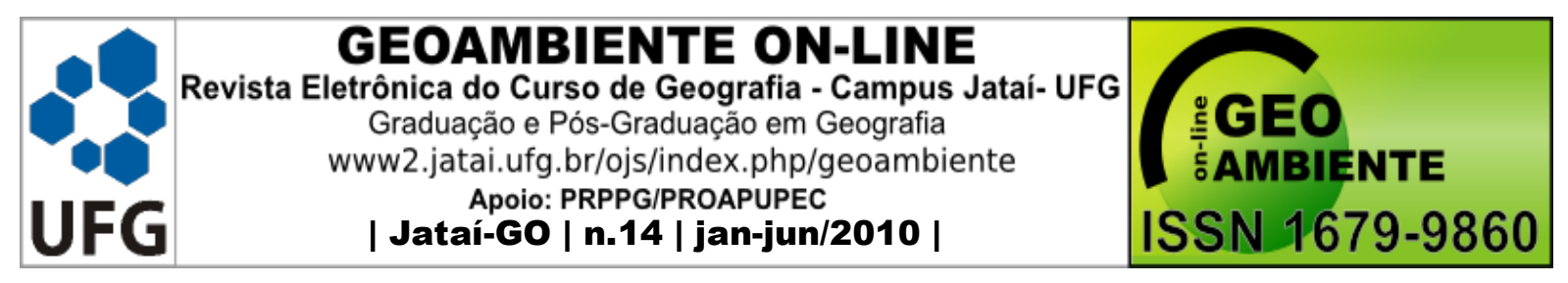

As condições paisagísticas atuais da praia do Jatobá em meio às ações humanas, que têm demonstrado interferência degradante, produzem acelerada vulnerabilidade biofísica ao ambiente, comprometendo a existência e distribuição das espécies, por sua vez fixadora do substrato. Ademais, as atitudes humanas tendem a produzir em curto prazo transformações mais intensas na fisionomia das dunas costeiras.

No âmbito da questão, é por meio do estudo da paisagem que se pode compreender a dinâmica peculiar do ecossistema. A paisagem integra processos naturais e aqueles em que o homem é o principal agente transformador. Consoante Mezzomo (2008), a paisagem permite analisar os distintos espaços, diferenciados entre si por causas naturais e antrópicas que mantém estreita relação.

A fragilidade em que se encontra o ecossistema dunar da Praia de Jatobá é resultante da sensibilidade deste sistema biótico e abiótico que sofre com a intensa depleção dos seus recursos por conta das práticas humanas. Seguindo a ideia de Mezzomo (2008), é nessa direção que a paisagem além de estar sujeita a mudanças, torna-se passível de transformar-se de forma irreversível.

O presente estudo objetiva apresentar o perfil fitogeográfico da Praia de Jatobá, município de Barra dos Coqueiros, Sergipe, bem como avaliar as condições paisagísticas atuais da localidade em função de sua relação com as ações antrópicas.

\section{2 - Distribuição Fitogeográfica nas Dunas Costeira}

A paisagem costeira está caracterizada pela diversidade de ecossistemas que a compõe de maneira singular. Para Cordazzo et al. (2006), o desenvolvimento das dunas litorâneas é comum em muitas praias arenosas. Esse ecossistema, consoante Ab' Saber (2006), ocorre desde o sul até o norte do país com extensões variadas que se intercalam com afloramentos rochosos.

A formação das dunas litorâneas está intimamente associada a fatores estruturantes e antrópicos. Faz-se necessário, portanto, estudar os elementos constituintes que contribuem para a existência do ecossistema e avaliar o nível de perturbações responsáveis pela degradação do mesmo, sejam estas por causas naturais ou antrópicas (OLIVEIRA, 2007). 


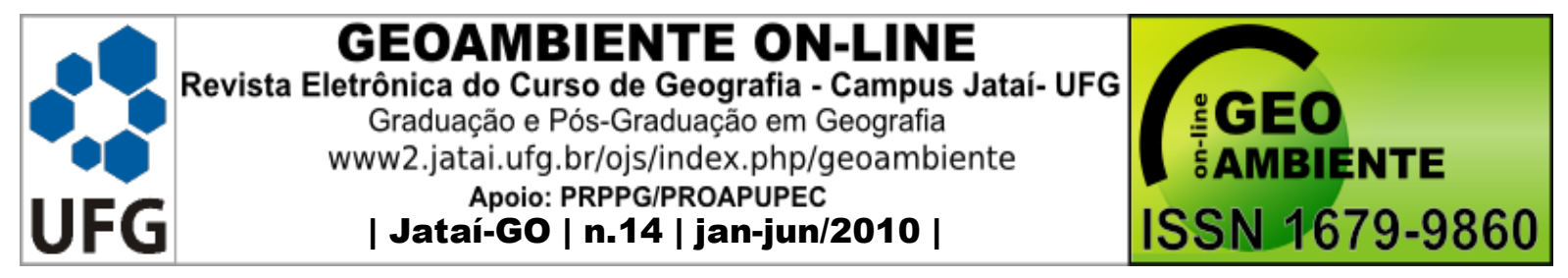

Em se tratando das condicionantes físicas que caracterizam as dunas, Cordazzo et al. (2006), afirma que a formação dos campos de dunas existe por intermédio da interação direta entre os ventos oceânicos dominantes e o deslocamento dos sedimentos. Com a deposição da areia realizada pelo mar nas altas marés, os sedimentos ficam sujeitos ao transporte, por conta dos ventos, depois de sua secagem, depositando-se somente no momento em que ocorrem alterações na topografia local, presença de barreira física ou de vegetação, que os impedem de continuar deslocando-se. Na ótica de Ab'Saber (2006), essa dinâmica ambiental faz das dunas um sistema relevante e distinto em meio às inúmeras paisagens do litoral brasileiro.

Neste cenário, os estudos biogeográficos permitem, conforme Brown \& Lomolino (2006), documentar e compreender modelos espaciais de biodiversidade. Ainda conforme estes autores, a biogeografia destaca-se por seu amplo campo de investigação científica. É neste sentido que a fitogeografia, como ramo da biogeografia, permite subdividir o território e estudar o funcionamento integrado das feições de dunas, que por sua vez classificam-se em dunas incipientes, dunas semi fixas e dunas fixas seguindo a linha do mar para o continente.

De acordo com Rizzini (1997), na faixa de praia, região sujeita às inundações das marés, as plantas estão ausentes, apesar de raramente alguns halófitos rasteiros aparecerem. Por outro lado, Rizzini (1997) afirma que na segunda faixa, que segue em direção ao continente, encontram-se as antedunas, as quais se situam entre o limite da maré de sizígia e o começo das dunas. Essa faixa, em alguns períodos do ano, é recoberta pelo mar, o que provoca a alta freqüência salina junto ao sedimento. As espécies vegetais quando estão presentes são ditas halófilas e reptantes e são dependentes das condições ambientais típicas desta faixa. Destacam-se a Blutaparon portulacoides, Hydrocotyle umbellata, Ipomoea pescaprae, Panicum racemosum, Paspalum vaginatum, Remirea maritima, Sporobolus virginicus, dentre outras espécies. É importante ressaltar que há uma faixa de transição ante dunar onde habitam espécies psamófitos reptantes, merecendo destaque Acicarpha spathulata, Canavalia obtusifolia, Hydrocotyle umbellata, Ipomoea pes-caprae, Sophora tomentosa etc.

Para Cordazzo et al. (2006), essa faixa ante dunar depende da variada amplitude de marés, o que faz com que a vegetação limite-se às dunas incipientes e que embora sofram influência direta das ressacas em períodos de inverno, conseguem estabelecer espécies anuais típicas das áreas de deposição de lixo, posto ser área de deposição de matéria orgânica. 


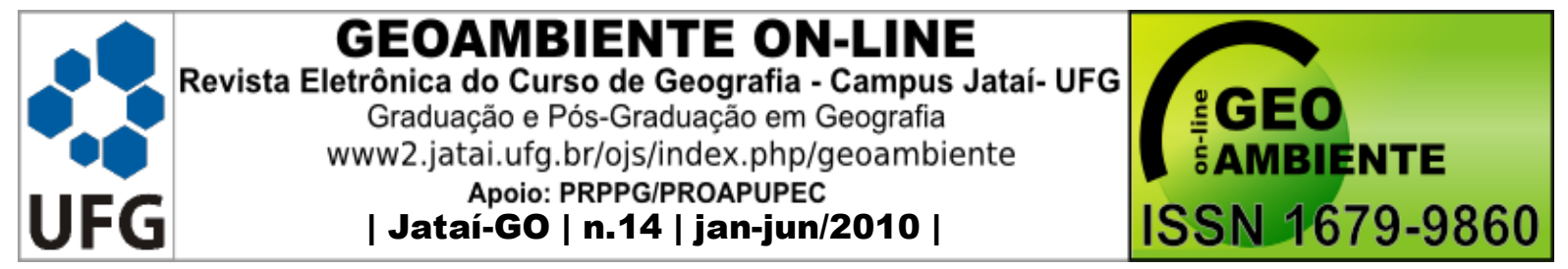

Destacam-se a Ckile maritima, ou espécies perenes com facilidades regenerativas por conta dos fragmentos do rizoma, a exemplo da Blutaparon portulacoides. Por outro lado, essas dunas incipientes podem ser ocupadas por espécies que apresentam variadas adaptações morfológicas, anatômicas, fisiológicas, reprodutivas, de ciclo de vida e tolerância à deposição dos sedimentos.

Ainda conforme Rizzini (1997), as dunas semifixas ou móveis são compostas por sedimento pobre em nutrientes. Nesta faixa as plantas são comumente xerófilas, rastejantes ou de pequenas dimensões e ainda estão sujeitas, para Cordazzo et al. (2006), à fortes estresses físicos. Rizzini (1997) cita espécies comumente encontradas nas dunas móveis, como Canavalia obtusifolia, Cenchrus pauciflorus, Dalbergia hecastophylum, Diodia radula, Diplothemium maritimum, Oxypetalum tomuntosum, Panicum racemosum, Paspalum maritimum, Sophora tomentosa, Stenotaphrum secundatum, Vigna luteola, dentre outras inúmeras espécies.

As dunas fixas são dotadas de substrato mais estável comparando-se à região de dunas móveis. Apresentam-se coberta por inúmeras espécies vegetais e demonstram maiores quantidades de biomassa com diminuição do $\mathrm{pH}$ em relação às paisagens supracitadas. A vegetação neste ambiente depara-se com as limitações impostas pela distância do lençol freático que determina a presença de algumas áreas secas e outras úmidas. Enquanto encontram-se Andropogon arenarius, Conyza floribunda, Gamochaeta americana, Hydrocotyle bonariensis, Plantago tomentosa, Polygala cyparissias e Senecio crassiflorus naquelas em nível de espécies abundantes, nestas últimas áreas expressam-se, principalmente, Androtrichum trigynum, Bacopa monnieri, Imperata brasiliensis, kyllinga vaginata, Spartina ciliata, Triglochim striata e Vigna luteola. É importante ressaltar que formas herbáceas como Acicarpha spathulata, Canavalia rosea, Ipomoea imperati, Remirea maritima, Sporobolus virginicus ocupam dunas fixas da região tropical com freqüência (CORDAZZO et al., 2006).

Segundo Assis (2000), as plantas, além de elemento primário essencial à vida, podem ser consideradas como reguladoras do equilibrado funcionamento do sistema ambiental onde estão localizadas em associação com os vários fatores pertencentes ao sistema. Os elementos do sistema dunar atuam conjuntamente para desenvolvimento das distintas feições 


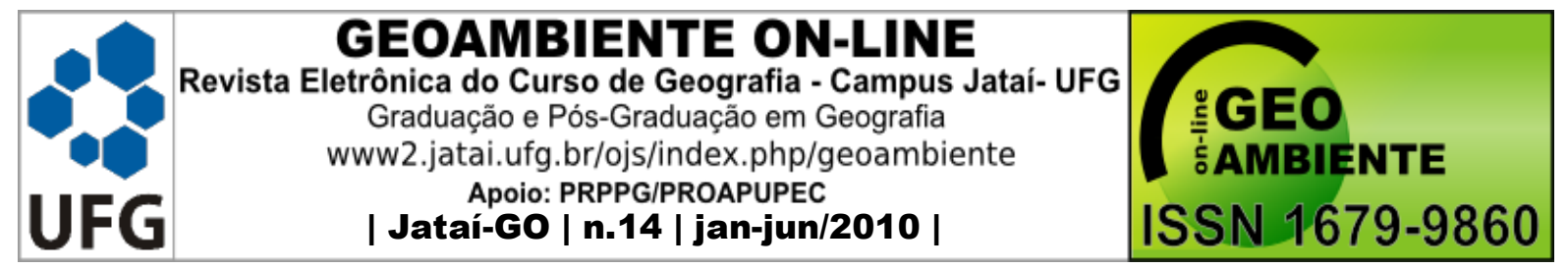

apresentadas pelo ecossistema e a vegetação destaca-se como elemento preponderante à formação e desenvolvimento das dunas

\section{3 - Dinâmica da Paisagem Dunar e Vulnerabilidade Biofísica}

Os estudos fitogeográficos consideram a vegetação como um dos principais elementos da paisagem. As plantas representam a ligação existente entre a parte física e a parte humana da biosfera, uma vez que em qualquer ambiente correspondem ao reflexo do clima e da ecologia locais (ROMARIZ, 2008).

A paisagem pode ser então reconhecida através da integração de elementos litológicos, climáticos, geomorfológicos, biológicos associados a interferências sócio econômica, políticas e culturais e resultado de constantes modificações de ordem natural ou antrópica que interferem cada vez mais na paisagem natural modificando-a continuamente, a ponto de transformar o cenário paisagístico e limitar a sobrevivência dos seres vivos que dependem da dinâmica da paisagem natural (RESENDE \& MELO e SOUZA, 2009).

Em Sergipe, as dunas têm passado por processos de transformações em suas características biofísicas face às alterações na estrutura e dinâmica desses ambientes. O homem tem contribuído fortemente para essa questão e inúmeras práticas de natureza socioeconômica destroem gradativamente o ecossistema de dunas e provocam mudanças no ambiente costeiro. Merecem destaque os conflitos relacionados à ocupação do solo, à crescente taxa populacional, à expansão urbana e industrial desenfreadas e o intensificado turismo que atua desordenadamente (MELO e SOUZA \& OLIVEIRA, 2006).

É relevante enfatizar que os danos provenientes das ações humanas caracterizam-se como os mais danosos ao meio natural, destacando que dentre os maiores contribuintes à vulnerabilidade biofísicas das dunas costeiras encontram-se as crescentes práticas ligadas ao extrativismo animal e vegetal, as inúmeras edificações urbanas, portuárias, de turismos e lazer, a ação indiscriminada da agricultura, pastagens e a silvicultura (MELO e SOUZA, 2003).

A significativa pressão de fatores de ordem natural ou humana sobre os sistemas biofísicos dunares implica em transformações capazes de impedir a auto regeneração dos 


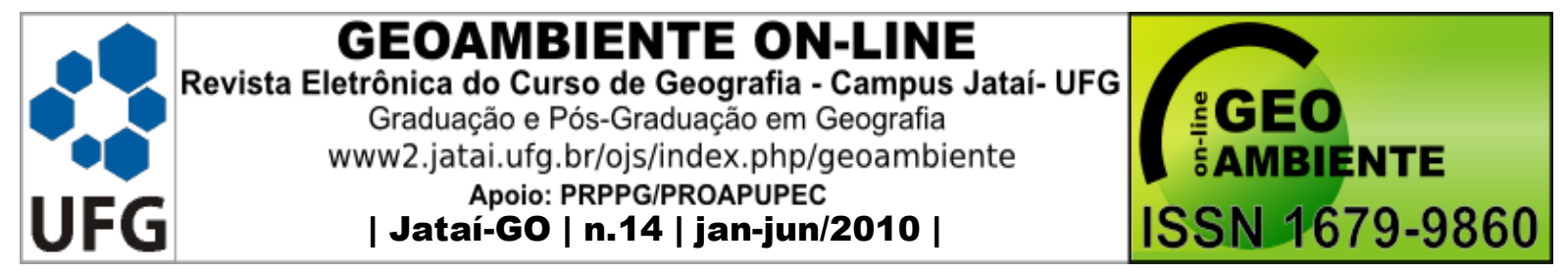

ambientes e de romper o equilíbrio particular da natureza (OLIVEIRA \& MELO e SOUZA, 2009).

No que se refere à retirada da vegetação, Cavalcanti (2008) descreve que esta prática expõe as camadas dos sedimentos à erosão, permite o carreamento dos estratos mais férteis e deixa descoberto as primeiras faixas do subsolo, este com menor fertilidade em relação às camadas mais superficiais do solo. Com isso, a produtividade deste último pode atuar de maneira decrescente de modo que seus componentes iniciais não retornem ao estágio inicial, interferindo na relação bio-físico-química entre a vegetação e solo e consequentemente na distribuição florística.

A transformação da paisagem natural em cultural atende necessariamente as necessidades humanas, visando principalmente à manutenção de um sistema econômico lucrativo, com necessidades ocupacionais do território natural. Entretanto, as práticas do homem não têm priorizado estudos e conhecimentos que visem à diminuição dos impactos ambientais a ponto de estabelecer medidas de preservação ambiental. Como resultado o que se observa é a contínua degradação dos componentes paisagísticos (REFOSCO, 1996).

\section{4 - Área de Estudo}

A área de estudo refere-se à Praia do Jatobá, no povoado Jatobá. Está localizada no município da Barra dos Coqueiros, estado de Sergipe (Figura 1), com distância de 18 Km à Nordeste da sede municipal da Barra dos Coqueiros. Este, com coordenadas geográficas

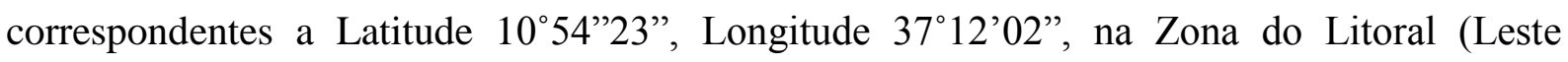
Sergipano) (PLANO DE DESENVOLVIMENTO URBANO DA BARRA DOS COQUEIROS, 2001). 


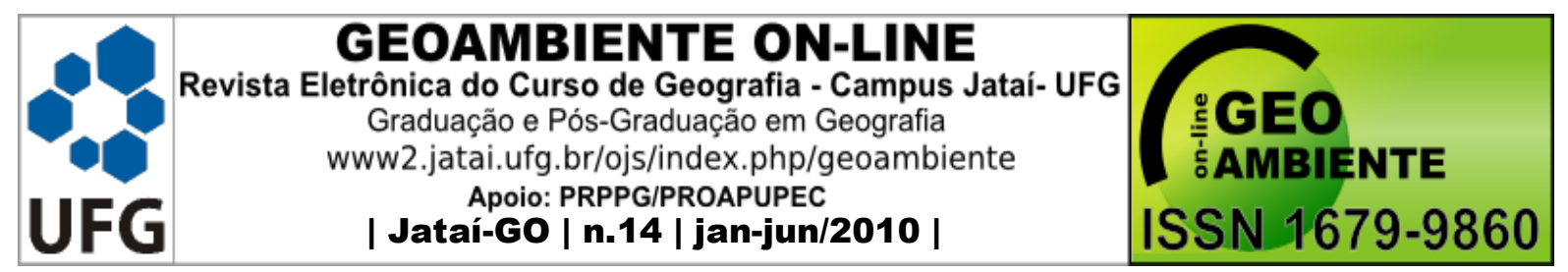

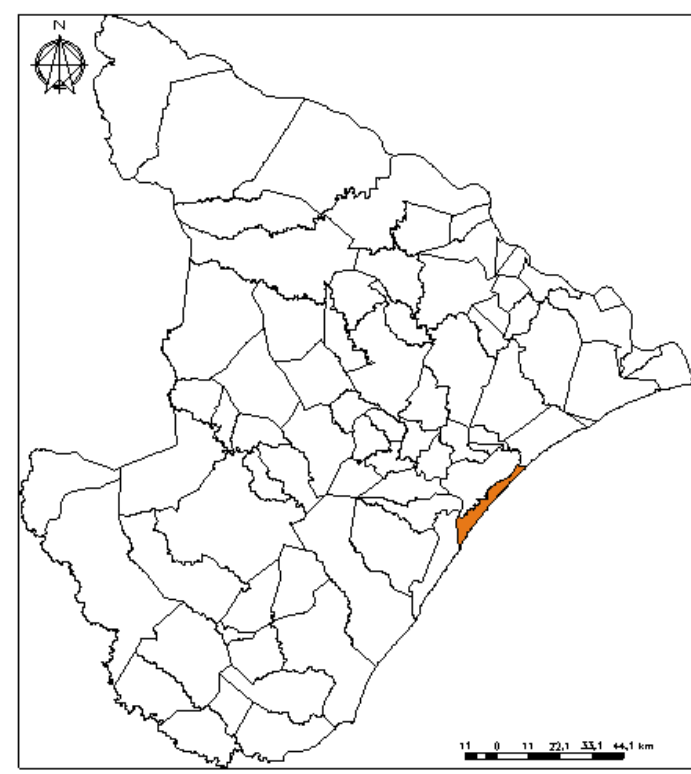

Município de Barra dos Coqueiros

Figura 1 - mapa do estado sergipano, com destaque para o município da Barra dos Coqueiros. Fonte: SUPES/SEPLAN (2006)

\section{5 - Procedimentos Metodológicos}

O trabalho contou com saídas de campo entre os meses de Outubro a Dezembro de 2008, correspondentes à estação da primavera, e no mês de Janeiro de 2009, já com a estação de verão.

A metodologia utilizada para delimitação da área de estudo corresponde à divisão de cada faixa, faixas de praia, de dunas incipientes, dunas semifixas e dunas fixas respectivamente, em transecto com $25 \times 25 m$ de dimensão, todos demarcados com uso de fita métrica e estacas, seguindo desta forma a metodologia de Scâffer adaptado por Melo e Souza (2003). A delimitação da área permite o mapeamento referente ao uso e à cobertura do solo pela vegetação através de técnicas de sensoriamento remoto e levantamentos paisagísticos na localidade. Nesta perspectiva, os pontos de estudo foram definidos com o auxílio do GPS Garmin Etrex Ouro e uso das estacas para demarcar as faixas estudadas.

Em cada transecto coletaram-se amostras das espécies vegetais presentes. Foram anotadas informações das estruturas morfológicas externas de cada espécie, prensando-as em seguida. As amostras foram conduzidas ao herbário ASE da Universidade Federal de Sergipe para identificação taxonômica. A flora coletada foi descrita em face de suas relações ecológicas peculiares e caracterizadas como nativas ou sinantrópicas. 


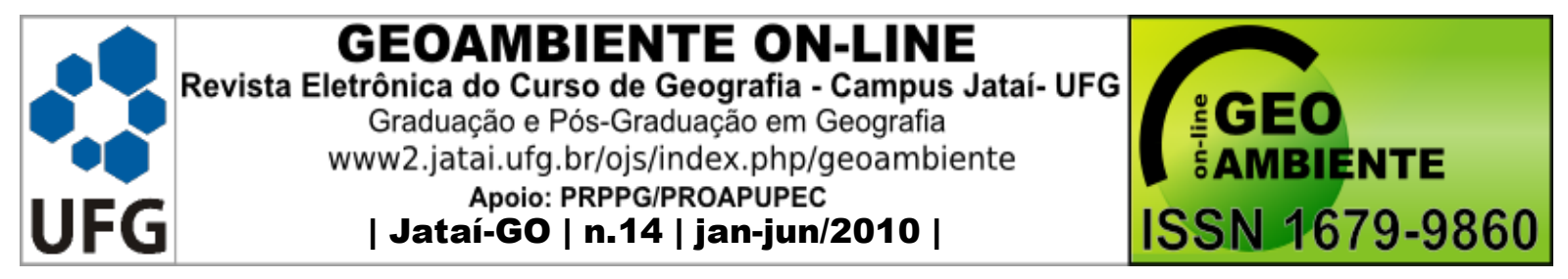

Foram feitas observações da localidade, a fim de maior entendimento dos aspectos fisionômicos e fitogeográficos da área de estudo da Praia do Jatobá. Dada a importância das ações humanas perante a natureza, as principais perturbações antrópicas que ocorrem na faixa de estudo foram observadas e analisadas.

\section{6 - Resultados e Discussão}

\subsection{Transecto 1 - Faixa de praia}

A primeira faixa da localidade delimitada para estudo corresponde à faixa de praia. Neste local é evidente a ausência de vegetação.

Neste primeiro transecto observou-se a presença de matéria orgânica no local. Conforme Cordazzo et al. (2006), a principal via de entrada de nutrientes no sistema dunar é a maresia ou o transporte de areia através do vento que carrega nutrientes adsorvidos do mar. Este autor ainda afirma que a matéria orgânica presente nesta faixa é essencial ao fornecimento de nutrientes na garantia de sobrevivência de plantas que se situam na próxima faixa, na direção mar continente.

Em decorrência da marcante presença do homem na localidade, a faixa correspondente expressa forte presença de lixo, como latas, recipientes de plástico, garrafas de vidro, sacos plásticos, jornal, material de barro (tijolo), dentre outros componentes deixados na praia por moradores ou turistas, provocando efeito negativo no integrado sistema praial.

Além do lixo deixado pelo homem, as ações antrópicas degradantes ampliam-se na localidade com a presença de veículos estacionados visualizados em dias de campo e trilhas dos carros que transitam pela faixa de praia.

\subsection{Transecto 2 - Faixa de dunas incipientes ou embrionárias}

A presença de dunas incipientes constituem a primeira barreira geográfica encontrada pelas marés.

Em meio ao período de observações e coletas que contou com as estações de primavera e verão, pôde-se visualizar a não inundação dessa área por parte das marés. Todavia, essa faixa ainda sofre forte influência marinha, apresentando espécies vegetais psamófilos halófitas que de acordo com a literatura de Cordazzo et al. (2006) estão sujeitas de 


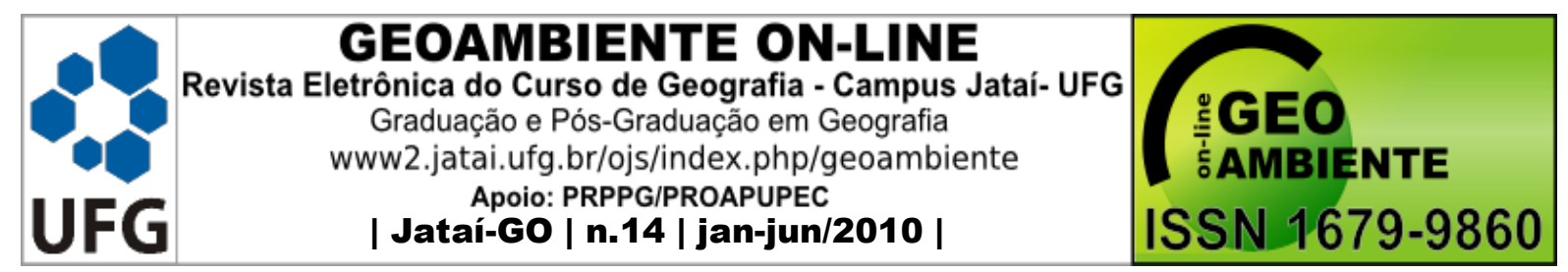

maneira estressante aos fatores ambientais, como vento, movimentação contínua da areia, salinidade, carência de nutrientes e estresse hídrico.

A fitofisionomia observada a partir do mês de outubro nesta faixa está representada pela vegetação herbácea, aspecto marcante das dunas embrionárias.

As espécies encontradas podem ser consideradas como tolerantes à deposição da areia, já que essa variável limita a sobrevivência da flora na faixa correspondente também, a exemplo da Ipomoea pes-caprae (L.) R. Br (Figura 2) e Paspalum maritimum Trin As raízes primárias e secundárias da Ipomoea pes caprae (L.) R. Br são profundas, o que indica a considerável importância da espécie quanto à fixação do substrato. Já a gramínea Paspalum maritimum Trin foi encontrada formando colônias sobre o substrato, dando o aspecto de manchas formadas pela espécie dentro do transecto. Juntamente com Ipomoea pes-caprae (L.) R. Br., a Paspalum maritimum Trin torna-se um obstáculo inicial para os ventos e iniciam a diferenciação da paisagem dunar.

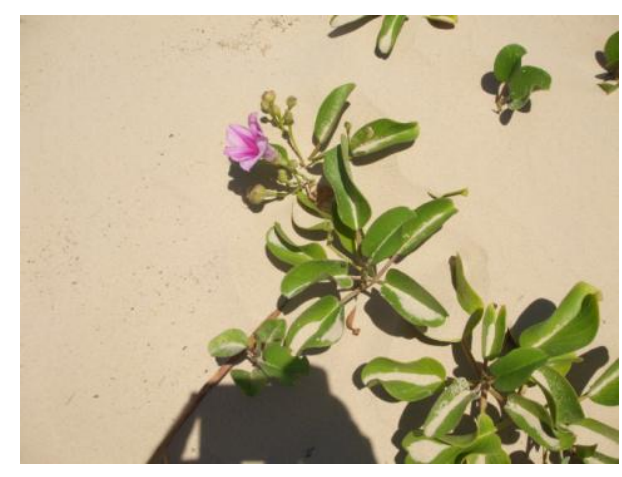

Fig 2: Ipomoea pes-caprae (L.) R. Br

Em face das observações da paisagem, em todas as visitas a presença do lixo foi contínua. Latas, garrafas plásticas e de vidro, sacos plásticos, dentre outros agentes prejudiciais à natureza foram encontrados nesta segunda faixa de estudo, assim como no primeiro transecto. Por outro lado, uma problemática existente nessa região é a barreira geográfica constituída por uma linha de casas e bares que percorrem a faixa do litoral atrás das dunas incipientes, a qual é interrompida apenas pela faixa (estrada) que dá acesso a praia. Esse fator interfere na dinâmica dos ventos que em associação com os sedimentos subsidiam a formação das posteriores dunas semifixas e fixas. 


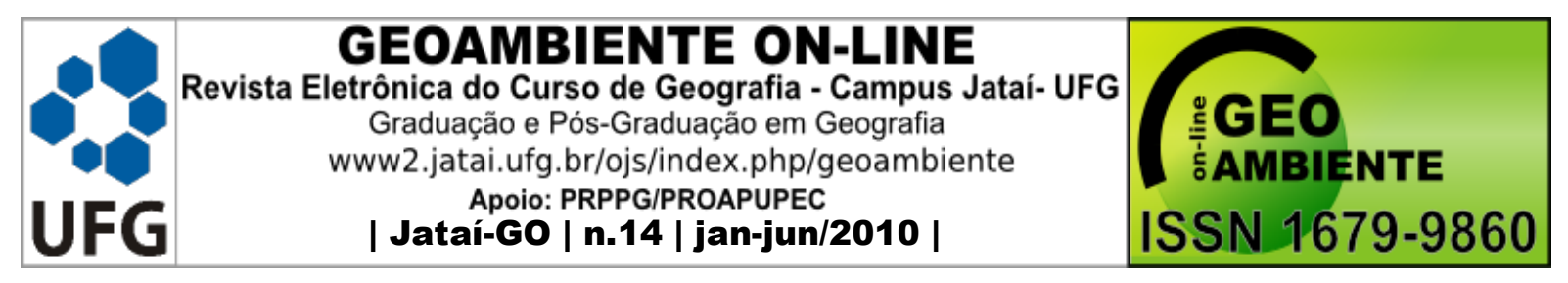

Outro agravo à vegetação nessa faixa de dunas visualizado durante os trabalhos de campo, mais precisamente na quarta visita, mês de Dezembro de 2008, foi o impacto estrutural concernente a presença do gado solto na praia, que além de pisotear as plantas dispostas na faixa em questão, usaram-nas como alimento alterando a composição da vegetação, e consequentemente a paisagem natural (Figura 3).

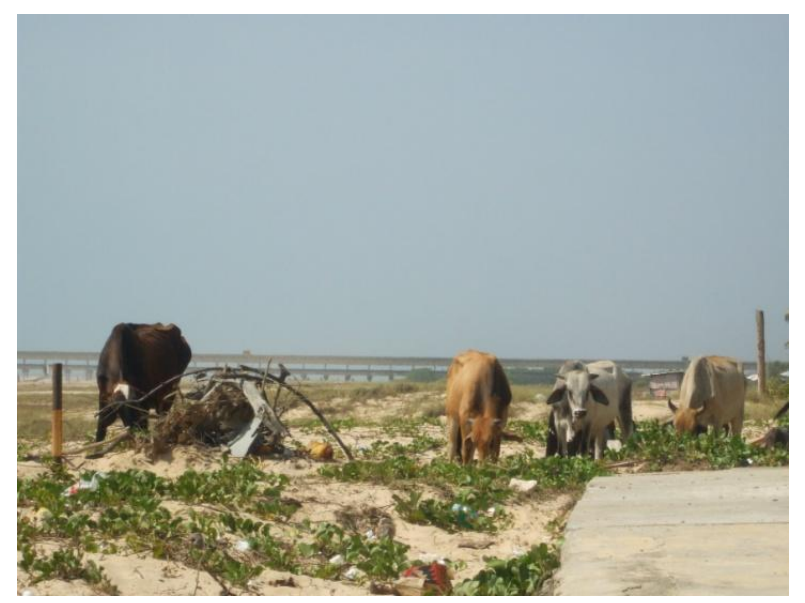

Figura 3 - Ação do gado sobre a vegetação da faixa de dunas incipientes.

No período supracitado, poucas flores da Ipomoea pes-caprae (L.) R. Br foram vistas, além disso, suas folhas demonstravam marcas da herbivoria. Em outro prisma, as colônias de Paspalum maritimum Trin mostraram um perfil de folhas secas e de poucas manchas no transecto.

\subsection{Transecto 3 - Faixa de dunas semifixas}

Seguindo o curso de observações da localidade, desde a primeira visita a Jatobá foi possível visualizar a paisagem que antecede este terceiro transecto.

Seguindo a partir das dunas incipientes, após a linha de edificações supracitadas, encontra-se uma estrada que segue a linha das casas e bares, além daquela que permite o acesso à praia na direção continente-praia. Posteriormente, será encontrado o primeiro sinal de dunas semi fixas em meio à paisagem (Figura 4). 


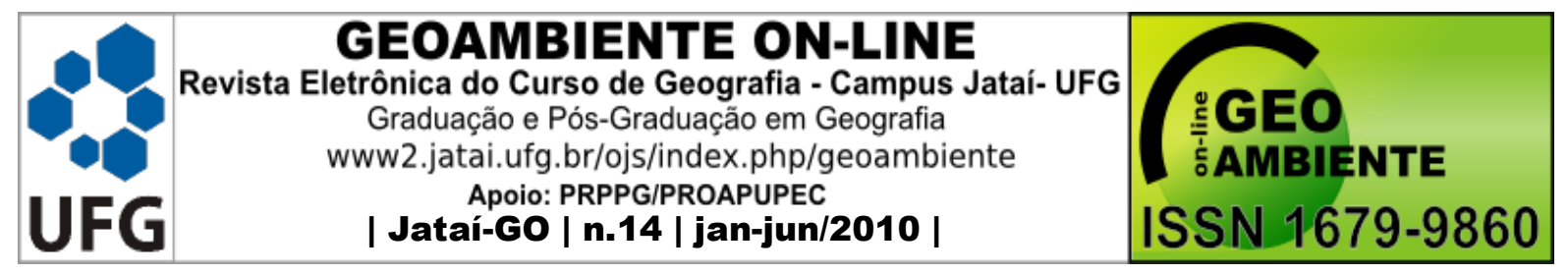

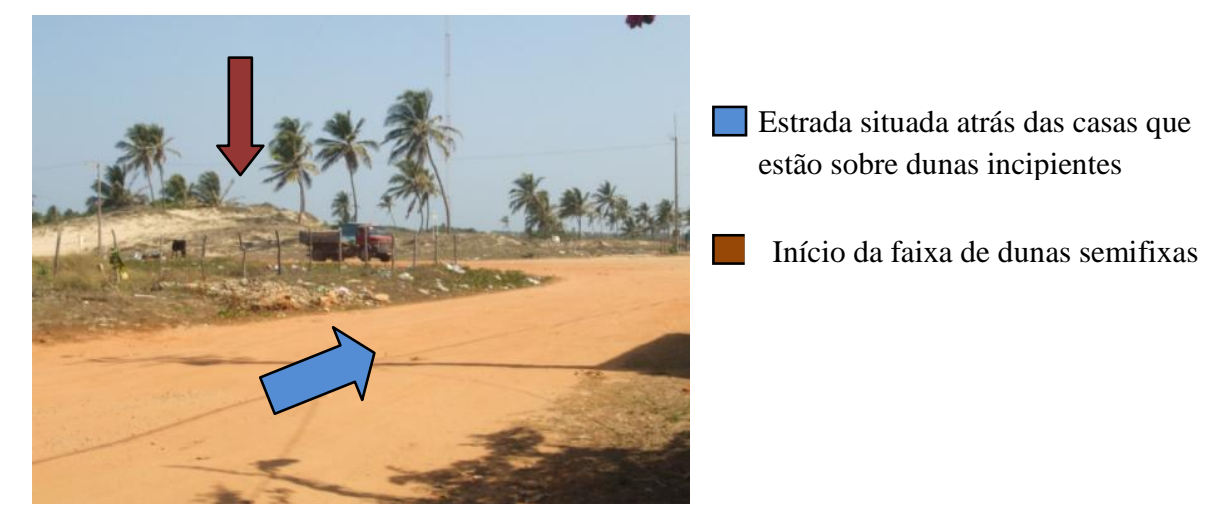

Figura 4 - Fisionomia da localidade com marcas antrópicas

Nas dunas semifixas da praia do Jatobá a fitofisionomia é marcada por vegetação herbácea e arbórea, exercendo, esta última, função protetora às espécies herbáceas que sofrem influência do sombreamento e desenvolvem-se mediante as condições de sombra.

Durante as duas coletas foram encontradas as espécies herbáceas Conocliniopsis prasiifolia (DC.) R.M. King \& H. Rob, Fabaceae sp., Poaceae sp. e Vernonia sp.

Durante o período de visitas que também corresponde aquele realizado nos transectos precedentes, a área de estudo apresentou aspectos de degradação antrópica. A poucos metros da localidade estudada são feitas queimadas constantes do lixo que é jogado na região diretamente no solo pela comunidade, o que acaba erodindo o substrato e destruindo a vegetação, que além de sofrer com as queimadas, lida com os reflexos da erosão do solo. A estrada que dá acesso à praia separa o ecossistema de dunas, e o que se observa é uma paisagem diferenciada e fragmentada neste trecho.

Outro problema que aqui se repete é a presença do gado solto atuando como agente de pisoteio e herbivoria da vegetação presente.

A quarta visita que contou com observações exibiu vegetação seca, mas as espécies identificadas fizeram-se presentes na localidade.

\subsection{Transecto 4 - Faixa de dunas fixas}

Percorrendo em direção ao continente os próximos pontos que limitam o quarto transecto equivale à área de dunas fixas. 


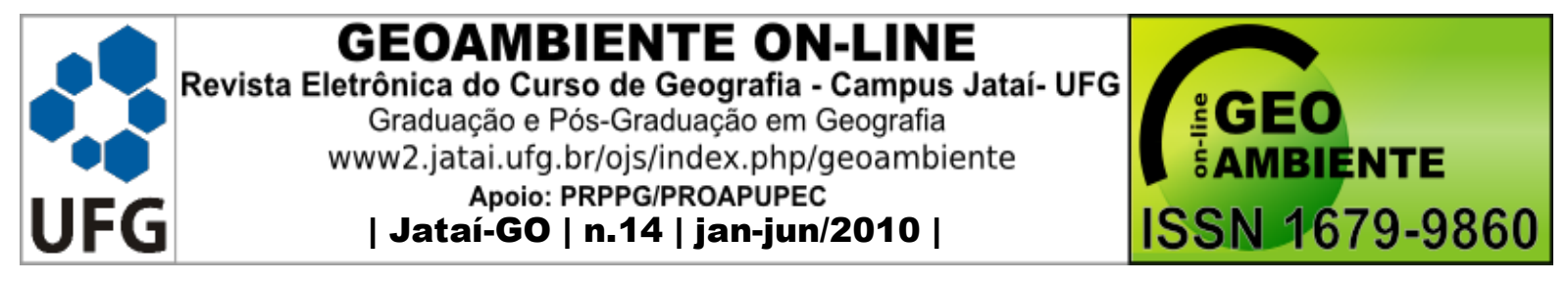

Quanto a fitofisionomia local, a vegetação arbustiva e herbácea faz-se presentes apesar desta última não ser tão expressiva no local. Por outro lado, observa-se a presença da espécie Cocos nucifera, expressando limitadamente vegetação arbórea.

A paisagem apresenta aspectos de mata de restinga, que também é comum na área da Praia do Jatobá, logo é possível encontrar espécies xerofíticas. Por outro lado, apesar da maior diversidade a paisagem apresentou muitas espécies com folhas secas.

As espécies coletadas na faixa correspondem a Borreria capitata (Ruiz \& Pav.) DC, Byrsonima sp, Malvaceae sp. e Vernonia sp.

A Vernonia sp. mostra-se dispersa pela área de dunas da praia do Jatobá e pôde ser encontrada tanto no terceiro como no quarto transectos.

No período de visitação não foi detectado lixo na faixa estudada, posto ser uma faixa de acesso mais difícil ao homem. Logo, as poucas práticas humanas nesta faixa a torna uma área de pouca intervenção humana no que concerne a presença do lixo.

\section{7 - Conclusão}

A dinâmica da paisagem na Praia do Jatobá evidencia contínuas e intensas alterações caracterizadoras de um ambiente em derivação antrpogênica em crescente vulnerabilidade biofísica, sobretudo pelas ações incidentes sobre as espécies psamófitas.

Os fatores preponderantes de derivação antropogênica e de incremento à vulnerabilidade biofísica dunar correspondem às queimadas realizadas nas dunas, no pisoteio e herbivoria do gado, no lixo jogado nas praias por banhistas, ou ainda depositado na faixa de dunas semifixas depois de uso doméstico pela comunidade, são fatores que comprometem o ecossistema de dunas da praia do Jatobá.

O acompanhamento da dinâmica da paisagem da área de estudo nos períodos de análise demonstra preocupação com os resultados de degradação acentuada, conforme a explicitação realizada ao longo deste trabalho. A presente situação do ecossistema dunar da Praia de Jatobá expressa às limitações oferecidas pelo sistema físico da localidade à vegetação. Em outro prisma, a ação antrópica também atua como fator de destruição gradativa do sistema dunar, comprometendo o equilíbrio ecológico da psamosere, compreendida como a sucessão ecológica em equilíbrio da vegetação psamófita. 


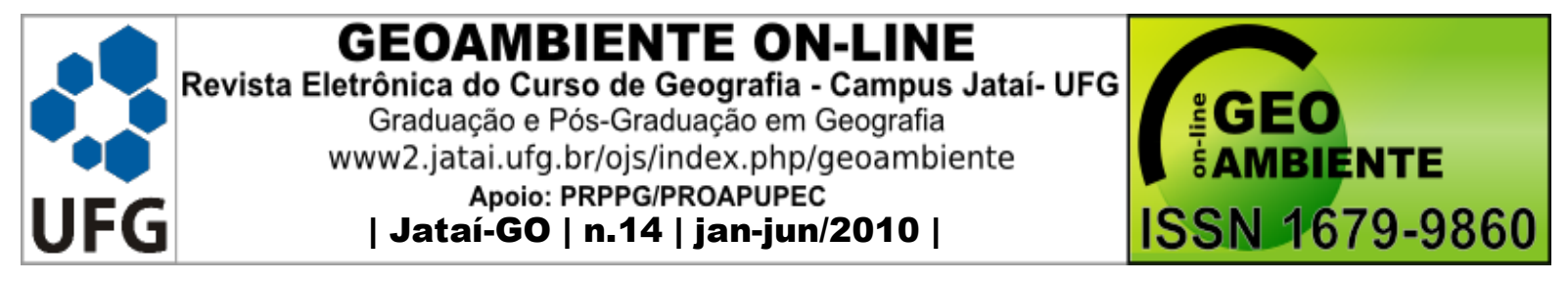

O estudo taxonômico da vegetação revela a distribuição das espécies ao longo dos segmentos dunares. Nessa perspectiva, o trabalho fitogeográfico é um instrumento basilar para o reconhecimento de espécies que ocupam o sistema de dunas. No prisma da análise a distribuição das espécies atua no equilíbrio existente entre o meio físico e biótico, atuando expressivamente no aspecto da paisagem dunar.

No tocante à dinâmica da paisagem, o estudo fitogeográfico torna-se relevante à medida que a vegetação é componente essencial da paisagem física. Além do mais é imprescindível reconhecer que o homem enquanto ser que compõe as paisagens faz parte da dinâmica do ecossistema dunar, remodelando-o a partir de suas necessidades. Entretanto, o que se deve considerar é que existem leis naturais que se integram e são responsáveis pelos efeitos da integridade do funcionamento sistêmico dos ambientes de dunas costeiras.

\section{8 - Agradecimentos}

As autoras agradecem o apoio do Herbário da UFS na identificação dos taxons.

\section{9 - Referências Bibliográficas}

AB’ SÁBER, A. Escritos Ecológicos. 2. ed. São Paulo: Lazuli, 2006.

AZEVEDO, D. V. Propostas de Manejo para a APA das Dunas de Lagoinha-ParaipabaCeará. 2005. 124 p. Dissertação (Mestrado em Desenvolvimento e Meio Ambiente). Prodema- Programa Regional de Pós-Graduação em Desenvolvimento e Meio Ambiente, PróReitoria de Pesquisa e Pós-Graduação, Universidade Federal do Ceará, Ceará, 2005.

BROWN, J. H; LOMOLINO, M. V. Biogeografia. 2 ed. rev. e ampl. Ribeirão Preto, SP: FUNPEC, 2006.

CAVALCANTI, A.P.B. Dinâmica da paisagem: uma análise integrada da planície flúvio marinha - area de proteção ambiental (APA) delta do rio parnaíba, piauí/maranhão - Brasil. Trabalho apresentado na Conferência da Terra "fórum internacional do meio ambiente" realizada na Universidade Federal da Paraíba, em João Pessoa, de 21 a 24 de maio de 2008.

CORDAZZO, C. V; PAIVA, J. B; SEELIGER, U. Guia Ilustrado Plantas das Dunas da Costa Sudoeste Atlântico. Pelotas: USEB, 2006. 


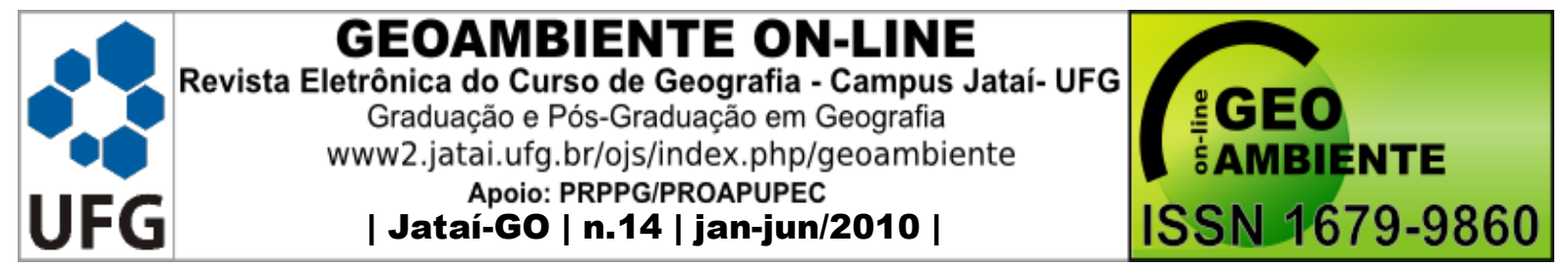

MELO e SOUZA, R. Indicadores biofísicos para monitoramento socioambiental na APA de Piaçabuçu-Alagoas. In: Congresso da Associação Brasileira de Estudos do Quaternário. IX, 2003, Recife, CD-Rom. Recife: Abequa, 2003.

MELO e SOUZA, R; OLIVEIRA, A. C. A. Risco Ambiental nos sistemas dunares de Aracaju. p. 183-185. In: ARAÚJO, H. M; VILAR, J. W. C; WANDERLEY, L. de L; MELO e SOUZA, R. (Org.). O Ambiente Urbano: visões geográficas de Aracaju. São Cristóvão: Departamento de Geografia da UFS, 2006.

MEZZOMO, M. M. Dinâmica da Paisagem e a organização das pequenas propriedades rurais em Marechal Cândido Rondon-PR. Geoambiente online - Revista Eletrônica do curso de Geografia do Campus de Jataí - UFG. Jataí-GO.n. 11. Jul-dez/2008.

OLIVEIRA, A.C. de A, MELO e SOUZA, R.. Geoindicadores Sociomabientais para monitoramento de dunas costeiras em Sergipe. R. RA'E GA, Curitiba. n. 14, p. 149-163, 2007. Editora UFPR.

PASSOS, Messias Modesto dos. Biogeografia e Paisagem. 2ºd. Maringá: [s.n], 2003.

PLANO DE DIRETOR DE DESENVOLVIMENTO URBANO - Barra dos Coqueiros, 2001.

REFOSCO, J. C. Ecologia da paisagem e Sistema de Informações Geográficas no estudo da interferência da paisagem na concentração de Sólidos Totais no reservatório da usina de Barra Bonita, SP. Anais VIII Simpósio Brasileiro de Sensoriamento Remoto, Salvador, Brasil, 14-19 abril 1996, INPE, p. 343-349.

RESENDE, W. X; MELO e SOUZA, R. Concepções e Controvérsias sobre áreas verdes urbanas. p. 43-45. In: MELO e SOUZA, R. (Org.). Território, Planejamento $e$ Sustentabilidade: conceitos e práticas. São Cristóvão: Editora UFS, 2009.

RIZZINI, C.T. Tratado de Fitogeografia do Brasil: aspectos ecológicos, sociológicos e florísticos. 2. ed. Âmbito Cultural Edições Ltda, 1997.

ROMARIZ, D. de A. Biogeografia: temas e conceitos. São Paulo: Scortecci, 2008. 


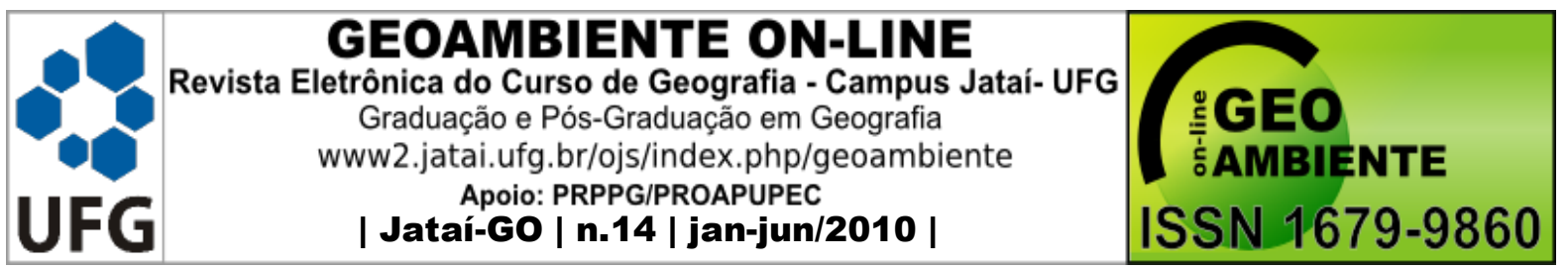

WANDERLEY, L. de L. Dunas da Zona de Expansão: condicionantes jurídicos e ambientais do uso e da ocupação. p. 210. In: ARAÚJO, H. M; VILAR, J. W. C; WANDERLEY, L. de L; MELO e SOUZA, R. (Org.). O Ambiente Urbano: visões geográficas de Aracaju. São Cristóvão: Departamento de Geografia da UFS, 2006. 